\title{
SPECIAL ISSUE - SOCIAL RESPONSIBILITY AND CONTINUITY IN FAMILY FIRMS
}

\author{
Guest Editors Introduction to the Special Issue \\ Julio Diéguez Soto and Ángela Callejón-Gil \\ Cátedra de Viabilidad Empresarial de la Universidad de Málaga
}

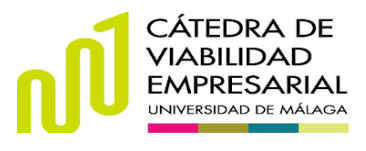

This Special Issue provides a collection of 6 papers, some of them presented at the 26th European Business Ethics Network (EBEN) National Conference, held in Málaga, Spain on the 31st of May and 1st of June, 2018. The title given to the 26th annual EBEN National Conference, hosted by the University of Málaga, was "The Work in the Role and Social responsibility of the Firm " and there was a specific track on "Ethic and Family Firms".

Some manuscripts presented to the National EBEN Conference, where were discussed, were selected as candidates to be published in the EJFB. Based on an editorial review, authors were invited to develop full manuscripts and present them at EJFB evaluation process. All received manuscript went through a double-blind review process.

In this issue, some articles addressed the role of motivation and opportunities of the employees in family firms, a specific subarea of firm 's social responsibility.

In the first article, Pimentel (2018) explores differences between non-family employees of family firms and employees of non-family firms regarding their levels of job satisfaction and assess the impact of non-family employees' perceptions of organizational justice on their levels of job satisfaction. This article reveals that in family firms, there is a positive influence of the perceptions of organizational justice on the job satisfaction levels, in particular regarding to the satisfaction with the benefits and with the supervision.

Likewise, an important contribution on career motivation and barriers in family business from daugthers' perspective is proposed by Akhmedova, Cavallotti and Marimon (2018), who found that daughters' motivation to act ethically is positively associated with high positions and that barriers "specific to family business" are negatively related to high positions.

On the other hand, in order to survive, family businesses should generate strategies to achieve firm continuity. In this issue, some articles are focused in competitive factors such as leadership, organizational culture, or labour factor. Likewise, the sixth article analysed the family business behaviour when addressing the protocol, which may increase the survival rate of family firms. Thus, Corrales, Ochoa and Jacobo (2018) confirmed that different types of leadership (expert, referential, laissez faire, participatory or autocratic) are present during distinct generations to pursue firm continuity. Vázquez Torres, Flores López and Ochoa Jiménez (2018) found that organizational culture influences positively innovation contributing to the survival of family firms. Likewise, Galego, Mira and Vidigal (2018) concluded that labour seems to be the main determinant of family firms' productivity, which is especially evident for firms in the mature stage. Finally, Rodríguez-Zapatero, Pérez, Rodríguez-Jiménez and Ramírez (2018) aim to explain the paradigm in which the intentionality to start the process towards the protocol on generational replacement and future distribution of the ownership is conducted by its feasibility - and this is partially marked by the willingness to reach the agreement and its utility.

We are hopeful that the works in this specific issue will help to enhance the understanding of social responsibility and firm continuity in family firms 


\title{
CONTENTS
}

\author{
Special issue. Social Responsibility and Continuity in Family \\ Firms \\ Guest Editors: Julio Diéguez Soto and Ángela Callejón-Gil
}

Non-family employees: levels of job satisfaction and organizational justice in small and medium-sized family and non-family firms

Duarte Pimentel

Barriers or motivation? Career progress in the family firm: daughters' perspective. Anna Akhmedova, Rita Cavallotti, Frederic Marimon

Leadership in the family business in relation to the desirable attributes for the successor: Evidence from Mexico.

Said Arath Corrales Villegas, Sergio Ochoa Jiménez, Carlos Armando Jacobo Hernández

The organizational culture of family enterprises and their relationship with innovation in the municipality of Cajeme, Mexico.

María del Carmen Vásquez Torres, José Guadalupe Flores López, Sergio Ochoa Jiménez

Ownership, productivity and a firms' life-cycle Destination Choice. Aurora Galego, Natércia Mira, Jacinto Vidigal da Silva.

Using PLS-SEM to model Family Business Behavior when addressing the protocol

Maribel Rodríguez Zapatero, Leonor Pérez Naranjo, Magdalena Rodríguez Jiménez, Isabel Ramírez Faz 